\title{
Using quantile regression to analyze the effect of renewables on EEX price formation
}

\author{
Lars Ivar Hagfors ${ }^{1,}$, Florentina Paraschiv ${ }^{2}$, Peter Molnar ${ }^{1}$, and Sjur Westgaard ${ }^{1}$ \\ ${ }^{1}$ Department of Industrial Economics and Technology Management, Norwegian University of Science and Technology, Norway \\ ${ }^{2}$ Institute for Operations Research and Computational Finance, University of St. Gallen, Switzerland
}

\begin{abstract}
This paper develops fundamental quantile regression models for the German electricity market. The main focus of this work is to analyze the impact of renewable energies, wind and photovoltaic, on the formation of day-ahead electricity prices for all trading periods in the EEX. We find that the renewable energy sources overall has a mild price dampening effect, and that the negative prices often attributed to wind power is a rare event that mainly occurs during nighttime periods of unusually low price and demand.
\end{abstract}

\section{Introduction and literature review}

Price dynamics for electricity markets has become increasingly complex as deregulation, market integration, and changes in input mix have taken place in different regions around the world. Electricity markets are characterized by mean reversion, seasonality, time varying volatility, jumps, positive skewness, high kurtosis and a complex relation to fundaments as the supply curve is convex and highly non-linear while the demand curve is almost in-elastic. Another complicating factor is that the input mix for power production might change over time (e.g. using more renewables), hence changing the dynamics for a given market over time. Considerable efforts have been performed from practitioners and academics trying to understand the price formation in different markets.

For consumers, suppliers, risk managers, traders and regulators concerned with market surveillance, modeling and forecasting the tails of the power price distributions is crucial when assessing risk. Risk in this context is usually measured by Value at Risk (VaR) or Expected Tail Loss (ETL) using information of the return/price distribution. At the same time, one is also interested in finding out how the different risk factors (supply and demand variables) influence different parts of the price distribution. The aim of this paper is to establish a model that enables us to perform such analysis.

In this paper, we analyze the impact of renewable energies, wind and photovoltaic, on the formation of dayahead electricity prices for different hours for the German (EEX) market using quantile regression. More specifically, we quantify the non-linear relationship between the renewables (and other supply/demand variables) on prices

\footnotetext{
* e-mail: Lars.i.Hagfors@iot.ntnu.no
}

at different hours. E.g. we can study how wind production influences the $5 \%$ price quantiles at hour 3 . The effect of a given variable will vary whether prices are high or low and whether we look at off-peak versus on-peak hours. According to our knowledge, no such study has been performed yet for the German market.

Our study is based on selected references investigating empirically how supply and demand variables influence the electricity price formation in different markets. In the Nord Pool market, references [1] and [2] study how Nord Pool market prices relates to water reservoir levels (in Nord Pool, hydro power is the dominant supply source). The estimation technique is non-linear regression capturing the shape of the convex supply curve. They argue that the marginal cost of hydro production varies depending on reservoir levels that determine hydro production capacity. The results show that higher reservoir levels, more hydro capacity, lead to significant lower power prices. They conclude that an increase in low marginal costs renewable power supply reduces the power prices and in the paper they demonstrate the numerical effects.

For the UK market, early studies by reference [3] applied a Markov regime-switching model, while reference [4] used a smooth transition logistic regression model investigating how fundamentals influence different periods of the day. Both studies give valuable insight into how sensitivities vary over time and parts of the day. Reference [5] introduced quantile regression for modeling the UK electricity price. By analyzing the period 38, they demonstrate how gas, coal, carbon prices, forecasts of demand and supply influence the electricity prices in a nonlinear way. They also demonstrated how the model could be used for Value-at-Risk forecasting, where this fundamental quantile regression model performed used as good as complex GARCH and CAViAR methods, although their approach was simpler to implement. Reference [5] does not address the distinctly different intraday characteristics 
hour by hour of the price risk distribution though. Yet it is well known that price formation (and hence risk) varies systematically throughout the day with different models generally being specified for peak, off-peak and mid-peak hours to reflect the dynamics of load following and the various technologies setting the marginal prices. With this in mind, reference [6] investigates all 48 half hourly prices from the UK market, across the range of quantiles from $1 \%$ to $99 \%$, estimated over the period 2005-2012. This paper also demonstrates the usage of scenario analysis where one can investigate how a change in one of the independent variables (e.g. forecast of demand) influences a specific period price quantile.

Regarding fundamental price models for the German market, [7] is a central reference. They find that the sensitivities of day-ahead electricity spot prices to the fundamental variables coal, gas, oil, and renewable energies, vary over time using a state space framework. They observe a continuous price adaption process of electricity prices to market fundamentals. Overall, the results show the importance of linking electricity spot prices to their fundamentals and suggest that purely stochastic models can be a too simplistic assumption. Since the input mix in Germany has changed over the last years, the paper also highlights the importance of a model allowing for timevarying sensitivities to fundamentals. They also show how the increase in the infeed from renewable energies, wind and $\mathrm{PV}$, led to a partial decrease in electricity day-ahead prices in Germany. This effect is noticeable for afternoon, evening and night hours in case of wind, and for noon peak hours, in case of PV. Furthermore, the inclusion of renewable energies improves considerably the explanatory power of the model. Additionally, renewable energies substitute the use in production of traditional fuels situated to the right of the merit order curve. In particular, the sensitivity of electricity prices to gas decreases over time. This fact becomes more visible for peak hours, due to the increase in the PV infeed.

Our paper is a combination of the quantile regression approach described in [5] and [6] applied on the dataset given in [7]. Since the German market has a different input mix than the UK market, we cannot simply transfer results from one study to another. Our aim is to investigate nonlinear relationship between fundamentals (particular wind and solar production) and prices and detect how the price distribution (hence risk) is influenced by the various drivers in the German market.

The paper is organized as follows. In Section 2, we offer a brief overview of the data and descriptive statistics. Section 3 describes the quantile regression models applied, and Section 4 discusses the preliminary results from these models. Finally, in Section Section 5 we conclude.

\section{Data}

The data used to estimate our model spans from January 1, 2010 to May 31, 2014 and consists of hourly data for most of the EEX specific market data and fundamentals and daily data for the main fuel sources. A brief overview of the variables used in the model is presented in Table 1 . We refer to [7] for a more detailed description and discussion of the relevance of each variable.

\section{Model}

The model used for our analysis is a quantile regression model $[8,9]$. This method allows us to investigate the relationship between the dependent and independent variables across the entire distribution, and provides us with a tool to get a better picture of how the fundamental factors affect the price in different quantiles.

The model is specified using levels, not natural logarithms. It is specifically set up this way to show how the relative impact of the fundamental factors in the model change across time and quantiles, with a particular interest for the lower extreme prices which some times reach negative numbers.

Letting $q \in(0,1)$ represent the different quantiles, $1 \%$, $5 \%, 10 \%, 25 \%, 50 \%, 75 \%, 90 \%, 95 \% 99 \%$, our linear quantile regression model will then be given by:

$$
\begin{aligned}
Q_{q}\left(P_{i, t}\right) & =\alpha_{i}^{q}+\beta_{i, 1}^{q} P_{i, t-1}+\beta_{i, 2}^{q} A V G_{-} S P O T \\
& +\beta_{i, 3}^{q} S P O T_{-} V O L+\beta_{i, 4}^{q} C O A L_{t-1}+\beta_{i, 5}^{q} O I L_{t-1} \\
& +\beta_{i, 6}^{q} E U A_{t-1}+\beta_{i, 7}^{q} E X \_W I N D_{t}+\beta_{i, 8}^{q} E X \_P V_{t} \\
& +\beta_{i, 9}^{q} Z_{i} E X \_P P A_{t}+\beta_{i, 10}^{q} E X D E M A N D_{t} \\
& +\beta_{i, 11}^{q} D E M A N D_{t},
\end{aligned}
$$

where

$i=1, \ldots, 24$ represents the 24 time periods throughout the day.

$Z_{i}=1$ for hours $7, \ldots, 21$ and 0 for the remaining hours.

We let $X_{i, t}$ be the 11-dimensional vector of independent variables. We can then rewrite the model as:

$$
Q_{q}\left(P_{i, t} \mid X_{i, t}\right)=\alpha_{i}^{q}+\beta_{i}^{q} X_{i, t} .
$$

We find the $q$ quantile regression coefficients for period $i$, $\bar{\alpha}_{i} q$ and $\bar{\beta}_{i} q$, as the solution to the following minimization problem:

$$
\min _{\alpha_{i}^{q}, \beta_{i}^{q}} \sum_{t=1}^{T}\left(Q-1_{P_{i, t} \leq \alpha_{i}^{q}+X_{i, t} \beta_{i}^{q}}\right)\left(P_{i, t}-\left(\alpha_{i}^{q}+X_{i, t} \beta_{i}^{q}\right)\right)
$$

where

$$
1_{P_{i, t} \leq \alpha_{i}^{q}+X_{i, t} \beta_{i}^{q}}= \begin{cases}1 & \text { if } P_{i, t} \leq \alpha_{i}^{q}+X_{i, t} \beta_{i}^{q} \\ 0 & \text { otherwise }\end{cases}
$$

The quantile regressions are estimated using STATA, using the sqreg command. A total of $216(9 \times 24)$ models have been estimated. This method estimates all the quantiles for any given hour simultaneously, generating a variance-covariance matrix that allows for meaningful comparisons of coefficients across quantiles. Standard errors are obtained via bootstrapping. 
Table 1. Brief overview of the data used in for the model. Refer to [7] for a full description.

\begin{tabular}{|c|c|c|}
\hline Variable, units & Description & Data source \\
\hline $\begin{array}{l}\text { Lagged spot price, EUR/ } \\
\text { MWh }\end{array}$ & $\begin{array}{l}\text { Market clearing price for the same hour of the } \\
\text { last relevant delivery day }\end{array}$ & $\begin{array}{l}\text { European Energy Exchange: } \\
\text { http://www.eex.com }\end{array}$ \\
\hline $\begin{array}{l}\text { Average lagged spot } \\
\text { price, EUR/MWh }\end{array}$ & $\begin{array}{l}\text { Average market clearing price across all } 24 \mathrm{~h} \text { of } \\
\text { the last relevant delivery day }\end{array}$ & $\begin{array}{l}\text { European Energy Exchange: } \\
\text { http://www.eex.com }\end{array}$ \\
\hline $\begin{array}{l}\text { Spot price volatility, } \\
\text { EUR/MWh }\end{array}$ & $\begin{array}{l}\text { Standard deviation of market clearing prices for } \\
\text { the same hour on the last five relevant delivery } \\
\text { days }\end{array}$ & $\begin{array}{l}\text { European Energy Exchange: } \\
\text { http://www.eex.com }\end{array}$ \\
\hline $\begin{array}{l}\text { Coal price, EUR/ } \\
12000 \mathrm{t}\end{array}$ & $\begin{array}{l}\text { Latest available price (daily auctioned) of the } \\
\text { front-month Amsterdam-Rotterdam-Antwerp } \\
\text { (ARA) futures contract before the electricity } \\
\text { price auction takes place }\end{array}$ & $\begin{array}{l}\text { Bloomberg, Ticker: GTHDAHD } \\
\text { Index }\end{array}$ \\
\hline Oil price, EUR/bbl & $\begin{array}{l}\text { Last price of the active ICE Brent Crude } \\
\text { futures contract on the day before the } \\
\text { electricity auction takes place }\end{array}$ & Bloomberg, Ticker: COA Comdty \\
\hline $\begin{array}{l}\text { Price for EUA, EUR } \\
0.01 / \text { EUA } 1000 \text { t } \mathrm{CO}_{2}\end{array}$ & $\begin{array}{l}\text { Latest available price of the EEX Carbon Index } \\
\text { (Carbix), daily auctioned at 10:30 am }\end{array}$ & $\begin{array}{l}\text { European Energy Exchange: } \\
\text { http://www.eex.com }\end{array}$ \\
\hline $\begin{array}{l}\text { Expected wind and PV } \\
\text { infeed, MWh }\end{array}$ & $\begin{array}{l}\text { Sum of expected infeed of wind electricity into } \\
\text { the grid, published by German transmission } \\
\text { system operators in the late afternoon following } \\
\text { the electricity price auction }\end{array}$ & $\begin{array}{l}\text { Transmission system operators: } \\
\text { http://www.50Hertz.com, http:// } \\
\text { www.amprion.de, http://www. } \\
\text { transnetbw.de, http://www. } \\
\text { tennestto.de }\end{array}$ \\
\hline $\begin{array}{l}\text { Expected power plant } \\
\text { availability, MWh }\end{array}$ & $\begin{array}{l}\text { Ex ante expected power plant availability for } \\
\text { electricity production (voluntary publication) } \\
\text { on the delivery day (daily granularity), } \\
\text { published daily at 10:00 am. }\end{array}$ & $\begin{array}{l}\text { European Energy Exchange and } \\
\text { transmission system operators: } \\
\mathrm{ftp}: / / \text { infoproducts.eex.com }\end{array}$ \\
\hline Expected demand, MWh & $\begin{array}{l}\text { Demand forecast for the relevant hour on the } \\
\text { delivery day as modeled in }[\mathrm{X}]\end{array}$ & $\begin{array}{l}\text { Own data, German Weather } \\
\text { Service: http://www.dwd.de }\end{array}$ \\
\hline Lagged demand, MWh & $\begin{array}{l}\text { Sum of total vertical system load and actual } \\
\text { wind infeed for the same hour on the last } \\
\text { relevant delivery day }\end{array}$ & $\begin{array}{l}\text { Transmission system operators: } \\
\text { http://www.50Hertz.com, http:// } \\
\text { www.amprion.de, http://www. } \\
\text { transnetbw.de, http://www. } \\
\text { tennestto.de }\end{array}$ \\
\hline
\end{tabular}

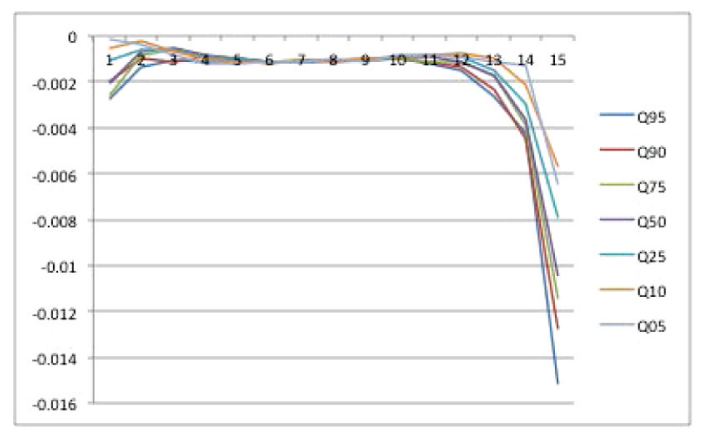

\begin{tabular}{|r|r|r|r|r|r|r|r|}
\hline \multicolumn{1}{l|}{ lour } & Q95 & Q90 & Q75 & Q50 & \multicolumn{1}{l|}{ Q25 } & Q10 & Q05 \\
\hline 6 & 0 & 0 & 0 & 0 & 0,01 & 0,458 & 0,864 \\
\hline 7 & 0 & 0 & 0 & 0 & 0,008 & 0,511 & 0,249 \\
\hline 8 & 0,001 & 0 & 0 & 0 & 0 & 0 & 0 \\
\hline 9 & 0 & 0 & 0 & 0 & 0 & 0 & 0 \\
\hline 10 & 0 & 0 & 0 & 0 & 0 & 0 & 0 \\
\hline 11 & 0 & 0 & 0 & 0 & 0 & 0 & 0 \\
\hline 12 & 0 & 0 & 0 & 0 & 0 & 0 & 0 \\
\hline 13 & 0 & 0 & 0 & 0 & 0 & 0 & 0 \\
\hline 14 & 0 & 0 & 0 & 0 & 0 & 0 & 0 \\
\hline 15 & 0 & 0 & 0 & 0 & 0 & 0 & 0 \\
\hline 16 & 0 & 0 & 0 & 0 & 0 & 0 & 0 \\
\hline 17 & 0 & 0 & 0 & 0 & 0 & 0 & 0 \\
\hline 18 & 0 & 0 & 0 & 0 & 0 & 0,001 & 0,004 \\
\hline 19 & 0 & 0 & 0 & 0 & 0 & 0 & 0,011 \\
\hline 20 & 0 & 0 & 0 & 0 & 0 & 0 & 0 \\
\hline
\end{tabular}

Fig. 1. Graphical representation of the coefficients for PV infeed for various quantiles, as well as the $P$-values for these coefficients.

\section{Results}

\subsection{PV infeed}

As shown in Figure 1, the coefficients for PV are found to be significant in the model for all but one extreme quantile. Overall, we observe that PV lowers the electricity market price. This is in line with the literature [7]. We observe a higher marginal effect of $\mathrm{PV}$ on the prices in higher quantiles. In the evening peak there is also, in absolute value, a higher marginal effect by PV on the market prices. Here we observe, to a larger extent, that the marginal effect in absolute terms increases with quantiles. Overall, PV reduces the chance of extreme spikes at EEX. 

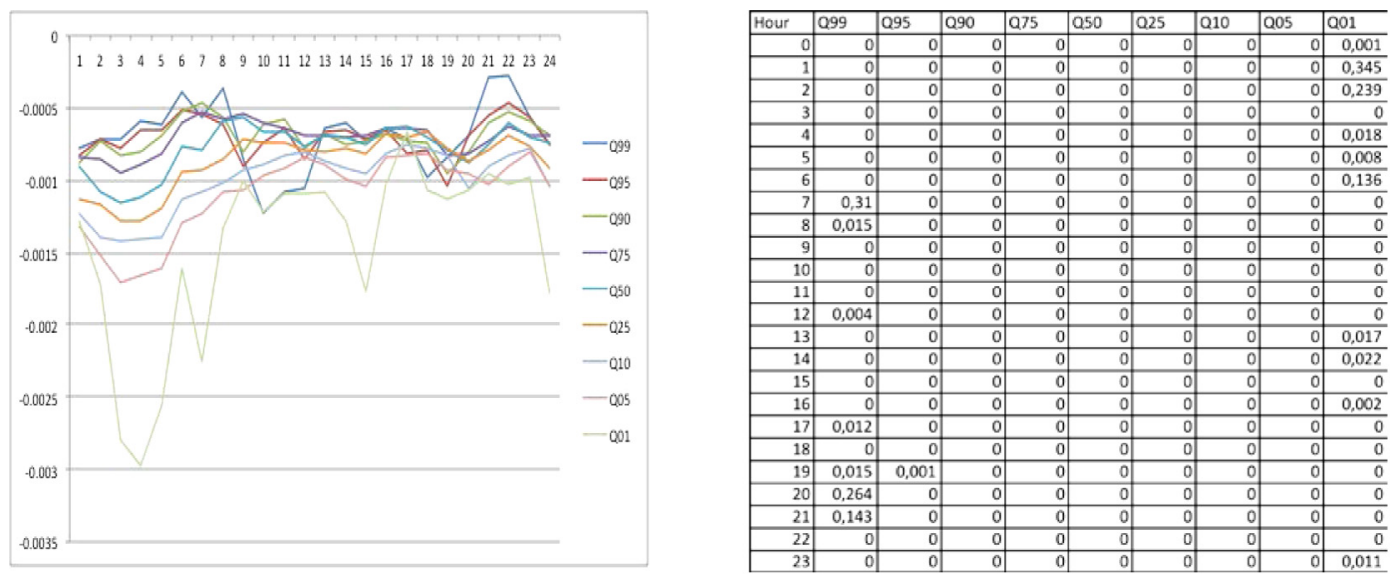

Fig. 2. Graphical representation of the coefficients for wind infeed for various quantiles, as well as the $P$-values for these coefficients.

\subsection{Wind infeed}

As shown in Figure 2, the coefficients for wind infeed is found to be significant in the model for all but a few cases of extreme quantiles in certain hours. According to historical price data from the EEX, negative prices occur mainly during the night hours. According to the literature, this is to a large extent caused by high wind infeed. This occurs because a large excess of electricity is produced night, when the demand is very low. For very low quantiles, often corresponding to where the negative price spikes are found, the marginal effect of wind is more powerful. Overall, we observe that wind decreases the electricity prices. During the night hours in particular, we observe that the marginal effects decrease in absolute values with the quantiles.

\section{Conclusions}

Using quantile regression, we have characterized the nonlinear effects of fundamental factors on the wholesale electricity price for each delivery period in the EEX. We confirm the complex market dynamics by demonstrating that the different factors vary substantially both across the trading periods and across the price distribution.

Even though this is just a preliminary study, we find clear indications that the renewable energy sources have a price dampening effect on the EEX. However, the negative spikes often attributed to wind production seems to be a rare event happening in low demand periods and not something that affects a large trading volume.

\section{References}

1. R. Huisman, V. Stradnicy, S. Westgaard, Renewable energy and electricity prices: indirect empirical evidence from hydro power, Working paper, Erasmus University, 2013

2. R. Huisman, D.W. Michels, S. Westgaard, Hydro reservoir levels and power price dynamics. Empirical insight on the nonlinear influence of fuel and emission cost on Nord Pool dayahead electricity prices, Working paper, Erasmus University, 2015

3. N.V. Karakatsani, D.W. Bunn, Fundamental and behavioural drivers of electricity price volatility, Stud. Nonlinear Dyn. Econom. 14, Article 4 (2010)

4. D. Chen, D. Bunn, Analysis of the nonlinear response of electricity prices to fundamental and strategic factors, IEEE Trans. Power Syst. 25, 595 (2010)

5. D. Bunn, A. Andresen, D. Chen, S. Westgaard, Analysis and forecasting of electricity price risks with quantile factor models, Energy J. 37, 101 (2016)

6. L.I. Hagfors, D. Bunn, E. Kristoffersen, T.T. Staver, S. Westgaard, Modelling the UK electricity price distributions using quantile regression, Working paper, NTNU, 2015

7. F. Paraschiv, D. Erni, R. Pietsch, The impact of renewable energies on EEX day-ahead electricity prices, Energy Policy 73, 196 (2014)

8. R. Koenker, G. Bassett, Regression quantiles, Econometrica: J. Econom. Soc. 46, 33 (1978)

9. S. Volgushev, M. Birke, H. Dette, N. Neumeyer et al., Significance testing in quantile regression, Electron. J. Stat. 7, 105 (2013) 